\title{
Physicochemical Properties and Plant Coverage of Wood-based Growing Media on Slopes ${ }^{1}$
}

\author{
Hong-Duk Moon $^{2} \cdot \mathrm{Si}$ Young $\mathrm{Ha}^{3} \cdot$ Ji Young Jung ${ }^{3} \cdot$ Jae-Kyung Yang $\mathbb{C}^{3, \dagger}$
}

\begin{abstract}
The use of wood waste as substrate for plant growth exemplifies a strategy for turning waste into resources. The overall objective of this research was to evaluate the effects of wood-based growing media on plant cover in a slope area. Moreover, we tried to find out what physicochemical properties affect plant cover on a slope. For treatments, we tested natural soil, soil mixed with wood-based growing medium (1:1, w/w), and wood-based growing medium by itself. Physical and chemical characteristics were evaluated after four months from the date of treatment application to the experimental slope site. Soil coverage with seedlings of Lespedeza cyrtobotrya was measured for plant growth evaluation. Physicochemical properties were altered by mixing the natural soil with wood-based growing medium. Particularly, soil moisture and organic matter contents were significantly changed in soils treated with wood-based growing medium compared to soil alone. We confirmed that plant coverage rate was high when wood-based growing medium was mixed with the natural soil. There was a significant linear relationship between moisture content and CEC (Cation Exchange Capacity) of all growth media tested and plant coverage. This result was expected, as moisture content tends to increase with organic matter content, such as in wood-based growing medium. In conclusion, the high moisture content of the wood-based growing medium was considered effective for plant growth in the experimental slope site, and this wood-based growing medium provides a means to improve the harmony between the slope and the surrounding environment.
\end{abstract}

Keywords: growing media, physicochemical properties, plant cover, slope area

\section{INTRODUCTION}

Vegetation has become a useful tool for restoring the physical conditions and stability of slopes during restoration processes. The presence of an initial plant cover will clearly be important to begin the process of stabilization and accumulation of organic material on the slope (Walker and Powell, 1999; Bardgett and
Walker, 2004). Besides, it is well known that vegetation effectively intercepts rain drops (Woo et al., 1997), increases water infiltration into the soil (Cerdò, 1998), and promotes slope-soil fixation by root systems (Gyssels and Poesen, 2003). Many factors, such as soil fertility, imbalanced nutrition, and disturbed soil properties, among others, limit slope plant cover worldwide. Soil properties influence soil basic functions,

\footnotetext{
${ }^{1}$ Date Received May 31, 2018, Date Accepted October 8, 2018

2 Department of Civil Engineering, Gyeongnam National University of Science and Technology, Jinju 52725, Republic of Korea

${ }^{3}$ Division of Environmental Forest Science, Institute of Agriculture \& Life Science, Gyeongsang National University, Jinju 52828, Republic of Korea

† Corresponding author: Jae-Kyung Yang (e-mail: jkyang@gnu.ac.kr, ORCID: 0000-0003-0423-6398)
} 
such as retaining water and promoting biodiversity. For example, top-soil organic content is fairly uniform over the greater part of a slope; however, there is usually a sharp increase at the foot of the slope, particularly over the last two to three seasons affected by periodic waterlogging (Furley, 1976). Continuous decomposition of organic matter in soils may ensure long-term survival of plants (Aggelides and Londra, 2000). Maintenance of soil properties is critical for ensuring the sustainability of the environment and the biosphere. To achieve successful long-term plant cover of cut slopes, the soil must be studied and understood. In particular, moisture, organic matter, bulk density and CEC (Cation Exchange Capacity), among physicochemical soil properties, reportedly affect each other (Raviv and Blom, 2001; Garcia-Gomez et al., 2002; Okiror et al., 2017). This means that it is important to understand the relationships between physicochemical properties to accurately characterize the soil. Growing media are used as base materials for plant growth in places where vegetation is severely limited, such as slopes (Jung et al., 2017). Growing media materials are formed by mixing various materials, such as soil improvement agents and food waste, in certain ratios (Cho et al., 2015; Park et al., 2016). However, there is little information on the application of growing media on slopes. The application of organic wastes, particularly wood waste, could be a way of solving two problems at once: on one hand, waste disposal, and on the other, the correction of the low organic matter content that prevails in many thin, slope soils. Among the reports related to soil application of organic wastes, only a small percentage deals with the improvement of soil physical properties and plant germination. To effectively use wood waste, Ogawa and Kuroda (1997) proposed a scheme to utilize charred wood waste as growing medium in agricultural lands. Moreover, wood waste is known to improve soil water content, increase soil $\mathrm{pH}$ and most major plant nutrient elements (Demeyer et al., 2001). Therefore, it is believed that wood-based growing medium has the potential to foster plant cover benefits on slopes. In addition to investigate the growth characteristics of green vegetation, we need to investigate growing media characteristics of slope soils, which is the basis for vegetation establishment, and for environmentally friendly and ecological slope greening (Park et al., 2006). Growing medium of the slope surface is the most important environmental factor affecting the growth of plants; therefore, it is necessary to investigate it, because of its decisive influence on the success of greening for the establishment and maintenance of plant communities (Kil et al., 2012).

Therefore, here an attempt was made to investigate various potential physicochemical properties and slope plant-coverage improvement methods by application of growing media. In addition, we analyzed the correlation between physicochemical properties and plant cover rate, and we tried to identify the physicochemical properties that affect plant cover on slopes.

\section{MATERIALS and METHODS}

\subsection{Site description and treatments}

The experiment was conducted at 1526, Gajwa-dong, Jinju-si, Gyeongsangnam-do, Republic of Korea. The experiment site has an ascent of forty degrees. This is a region with annual rainfall of $1500 \mathrm{~mm}$ and the maximum and minimum temperature $24.9{ }^{\circ} \mathrm{C}$ (August) and $0.9{ }^{\circ} \mathrm{C}$ (January). The experiment was laid out in randomized complete block design in triplicate. The plot size was $1 \mathrm{~m} \times 1 \mathrm{~m}$ with 2,000 plants plot $^{-1}$ plantseeds (Lespedeza cyrtobotrya).

\subsection{Preparation of wood based growing media}

The steam exploded oak wood (Quercus mongolica) $\left(1.5 \mathrm{~kg} / \mathrm{cm}^{2}, 5 \mathrm{~min}\right)$ was used as wood chip material 
Table 1. Composition of all growing media treatments used in the experiment

\begin{tabular}{lll}
\hline Media & Soil $^{1)} \%$ & Wood-based growing medium ${ }^{2)}$, \\
\hline \hline Natural soil & 100 & - \\
Soil mixed with wood-based growing medium $(1: 1$, w/w) & 50 & 50 \\
Wood-based growing medium & - & 100 \\
\hline 1) Soil at the experimental site & \\
2) Wood waste was mixed with peat and perlite at a rate of 3:1:6, on a dry weight basis.
\end{tabular}

for wood based growing media production. The steam exploded wood chip was mixed with peat and perlite at the rate of 3 wood waste : 1 peat : 6 perlite based on dry weight. The raw materials used in this study included commercial peat, classified as brown peat $(\mathrm{pH}$ 3.5-4.5, Satis International Co., Ltd. LA FLORA, Europe), and commercial perlite (particle size $2 \mathrm{~mm}$; Landscape Architecture Co., Ltd., Kore a). Mixed ratio of soil and wood based growing media used in the experiment is given in the Table 1 . All media were applied to the slope in 15 July 2015.

\subsection{All media collection and determination}

\subsubsection{All media collection}

All media (soil alone, soil with wood based growing media (1:1, w/w) and wood based growing media) were collected on 15 November 2015 (after 4 months from applied date of all media on experiment site). All media collection were by randomized sampling followed an experimental design. Three soil cores were taken from each replicate of the individual treatments to depth of $15 \mathrm{~cm}$, and then combined to a composite all media for each replicate. After sampling, the soil was sieved $2 \mathrm{~mm}$, mixed and air-dried for physicochemical analysis.

\subsubsection{Physical properties}

The bulk density was measured using the core method (Blake and Hartge, 1986). The moisture content was established using Medina et al. (2009) method and oven drying to constant weight at $105 \pm 5^{\circ} \mathrm{C}$ for $12 \mathrm{~h}$.

\subsubsection{Chemical properties}

The all media were analyzed for total organic matter by the dry combustion method at $540{ }^{\circ} \mathrm{C}$ (Nelson and sommers, 1982). The $\mathrm{pH}$ and electrical conductivity (EC) were analyzed in a 1:5 $(\mathrm{v} / \mathrm{v})$ water extract and measured using a pH meter (HI8418, HANNA, USA) and EC meter (LQ2-LE, Vernier, China), respectively (European Standard 13037, 1999). The C and N concentrations were analyzed by Kjeldahl digestion (Bremner and Mulvaney, 1982) using macro elemental analyzer (vario MACRO cube, USA). Available P was extracted with water or $\mathrm{CaCl}_{2}$ and measured by UV-Spectrophotometer at $840 \mathrm{~nm}$. The cation-exchange capacity (CEC) was determined with $1 \mathrm{M}$ ammonium acetate at $\mathrm{pH}=7$ (Soil Conservation Service, USDA, 1972).

\subsection{Plant coverage}

Plant coverage was calculated using an image taken by a Pentax K-R camera designed to calculate plant coverage. Exposure and aperture mode as well as the white balance were set to automatic. We collected images once a month from July to November and then calculated plant coverage using Adobe Photoshop CS5. The proportional values for the plant coverage were calculated using the following formula:

$$
\text { Plant coverage }(\%)=\frac{\text { Green color area }}{\text { Surface area }} \times 100
$$

Since the plant coverage was expressed as a proportional value, we refer hereafter to this as greenness or percentage greenness for clarity. 


\subsection{Correlation analysis}

To fulfill the objective of the study, the results out of laboratory experiments carried out were studied and were analyzed statistically. The relationships between Pearson's correlation coefficients were determined for the correlation matrix of all the physicochemical properties and plant coverage. All statistical analyses were performed with statistical package $\mathrm{R}$ 3.1.1, with a significance level of $p<0.05, p<0.01$ and $p<0.001$. To build the relation between soil properties linear regression model is used through excel.

\subsection{Data analysis}

Data were analyzed using SAS statistical software comparing data means to Duncan's test. Duncan's multiple comparison range test was used to determine significant differences between the means. The measurements were carried out for three replicates, and values are an average of the three replicates. The results are expressed as mean values \pm standard deviation (SD) for three replicates.

\section{RESULTS and DISCUSSION}

\subsection{Physical properties of the experimental growing media}

Table 2 shows the physical properties of experimental media tested in this study, which included, natural soil, soil mixed with wood-based growing medium (1:1, $\mathrm{w} / \mathrm{w}$ ), and wood-based growing medium all by itself. Bulk density is the degree of compactness of the substrate per unit volume; it reflects the substrate consistency and pore size, whereby it has great influence on soil aeration, water-holding capacity, infiltration capability, solute migration characteristics and antierosion resilience (Zhang and Zhao, 2015). Bulk density of the natural soil was higher than that of the other media tested. Wood-based growing media had lower bulk density compared to the natural soil. Its low bulk density can be associated with its high moisture content (Stabnikova et al., 2005). Hence, addition of woodbased growing medium to the soil may alleviate excessive compactness of the latter, while improving its physical properties; thus, making it a better substrate for plant growth. As expected, these properties improved under drier conditions, because moisture is a better conductor than air (Castleton et al., 2010). Usually soil moisture content is expressed as a percentage of oven-dry weight. As a result, wood-based growing medium showed the highest moisture content (57.9 \%) while natural soil showed the lowest moisture content (3.5\%). KramerPaul (1994) reported that the relationship between soil moisture content and plant growth could be expressed more advantageously on a volume basis. Therefore, wood-based growing medium was considered to be more beneficial to plant growth than soil alone.

Table 2. Physical properties of experimental growth media after 4 months from date of application of all growing media treatments at the experimental site

\begin{tabular}{lll}
\hline Media & Bulk density $\left(\mathrm{g} / \mathrm{cm}^{3}\right)$ & Moisture content $(\%)$ \\
\hline \hline Natural soil & $1.15 \pm 0.01 \mathrm{a}^{1)}$ & $3.5 \pm 0.1 \mathrm{c}$ \\
$\begin{array}{l}\text { Soil mixed with wood-based growing medium } \\
(1: 1, \text { w/w) }\end{array}$ & $0.16 \pm 0.00 \mathrm{~b}$ & $25.4 \pm 0.2 \mathrm{~b}$ \\
Wood-based growing medium & $0.12 \pm 0.00 \mathrm{c}$ & $57.9 \pm 0.2 \mathrm{a}$ \\
\hline
\end{tabular}

1) \pm Standard deviation, $\mathrm{n}=3$. Means followed by different letters within columns were significantly different $(p<0.05)$ 


\subsection{Chemical properties of the experimental growing media}

Low organic matter content was observed in the natural soil (6.8\%), but soil mixed with wood-based growing medium (1:1, w/w) and wood-based growing medium by itself showed organic matter contents between $68.4 \%$ and $84.8 \%$ (Table 3). Organic matter is one of the most important soil factors, because of its capacity to affect plant growth indirectly (as it improves the physical conditions of soil by enhancing aggregation) and directly (by creating a suitable environment for plant root growth) (Senesi and Loffredo, 1999). Therefore, we concluded that the wood-based growing medium was suitable as a substrate for effectively fostering plant growth. The $\mathrm{pH}$ of all three media tested was acid, with the highest value (5.43) found in soil without any addition. It is generally accepted that optimal $\mathrm{pH}$ for healthy growth of most plants lies between 6.5 and 7.0 (Smith, 1994). Therefore, the $\mathrm{pH}$ of all media tested here was too low and thus, required adjustment towards neutrality. The EC (Electrical Conductivity) of wood-based growing medium was very high, compared to EC of the soil. Wright (1986) reported that recommended EC value ranges between 0.6 and $2.0 \mathrm{mS} / \mathrm{cm}$ for healthy and vigorous plant growth. Soil
EC was $0.66 \mathrm{mS} / \mathrm{cm}$, while soil mixed with wood-based growing medium $(1: 1, \mathrm{w} / \mathrm{w})$ showed an EC value of $1.86 \mathrm{mS} / \mathrm{cm}$, both wood-based growing medium exceeded them both with an EC of $2.91 \mathrm{mS} / \mathrm{cm}$. EC values above $3.5 \mathrm{mS} / \mathrm{cm}$ are often too high to support vigorous plant growth in containers (Lemaire et al., 1985). However, Chong et al. (1991) reported good growth of several woody species in media with EC values exceeding $8 \mathrm{mS} / \mathrm{cm}$. Therefore, we concluded that wood-based growing medium should not be a problem for plant growth in regard to EC. The ratio of carbon to nitrogen $(\mathrm{C} / \mathrm{N})$ is the parameter most often considered in wood-based growing medium. The ranking for $\mathrm{C} / \mathrm{N}$ ratio in our study was wood-based growing medium (8.5) > soil mixed with wood based-growing medium (5.4) > soil (1.0). The high $\mathrm{C} / \mathrm{N}$ ratio in wood-based growing medium may be explained by immobilization of N (Rosen et al., 1993). Some authors have suggested that the $\mathrm{C} / \mathrm{N}$ ratio is an extremely important property in the decomposition of organic matter by microorganisms (Marin, 2004). Consequently, the wood-based growing medium tested was considered suitable for promoting plant growth.

Available P content was calculated as 2.1, 5.4, and $10.7 \mathrm{~g} / \mathrm{kg}$ for soil, soil mixed with wood-based growing medium (1:1, w/w), and wood-based growing medium,

Table 3. Chemical properties of experimental growing media after 4 months from date of application of all growing media treatments at the experimental site

\begin{tabular}{|c|c|c|c|c|c|c|}
\hline Media & $\begin{array}{l}\text { Organic matter } \\
(\%)\end{array}$ & $\mathrm{pH}$ & $\begin{array}{l}\mathrm{EC} \\
(\mathrm{mS} / \mathrm{cm})\end{array}$ & $\mathrm{C} / \mathrm{N}$ & $\begin{array}{l}\text { Available P } \\
\text { (g/kg) }\end{array}$ & $\begin{array}{l}\text { CEC } \\
\text { (c } \mathrm{mol} / \mathrm{kg})\end{array}$ \\
\hline Natural soil & $\begin{array}{l}6.8 \\
\pm 0.3 c^{1)}\end{array}$ & $\begin{array}{l}5.43 \\
\pm 0.06 \mathrm{a}\end{array}$ & $\begin{array}{l}0.66 \\
\pm 0.50 \mathrm{c}\end{array}$ & $\begin{array}{l}1.0 \\
\pm 0.0 \mathrm{c}\end{array}$ & $\begin{array}{l}2.1 \\
\pm 0.0 \mathrm{c}\end{array}$ & $\begin{array}{l}23.0 \\
\pm 0.9 \mathrm{a}\end{array}$ \\
\hline $\begin{array}{l}\text { Soil mixed with } \\
\text { wood-based } \\
\text { growing medium } \\
(1: 1, w / w)\end{array}$ & $\begin{array}{l}68.4 \\
\pm 15.7 b\end{array}$ & $\begin{array}{l}2.53 \\
\pm 0.01 \mathrm{~b}\end{array}$ & $\begin{array}{l}1.86 \\
\pm 0.10 \mathrm{~b}\end{array}$ & $\begin{array}{l}5.4 \\
\pm 0.0 \mathrm{~b}\end{array}$ & $\begin{array}{l}5.4 \\
\pm 0.4 \mathrm{~b}\end{array}$ & $\begin{array}{l}27.8 \\
\pm 0.3 a\end{array}$ \\
\hline $\begin{array}{l}\text { Wood-based } \\
\text { growing medium }\end{array}$ & $\begin{array}{l}84.8 \\
\pm 0.9 \mathrm{a}\end{array}$ & $\begin{array}{l}2.64 \\
\pm 0.02 b\end{array}$ & $\begin{array}{l}2.91 \\
\pm 0.10 \mathrm{a}\end{array}$ & $\begin{array}{l}8.5 \\
\pm 0.0 \mathrm{a}\end{array}$ & $\begin{array}{l}10.7 \\
\pm 0.9 \mathrm{a}\end{array}$ & $\begin{array}{l}29.2 \\
\pm 0.3 \mathrm{a}\end{array}$ \\
\hline
\end{tabular}

\footnotetext{
${ }^{1)} \pm$ Standard deviation, $\mathrm{n}=3$. Means followed by different letters within columns were significantly different $(p<0.05)$
} 
respectively. Phosphorus is known to be one of the most important elements and essential nutrients for plant growth (Orhan et al., 2006). As wood based-growing medium is highest in available $\mathrm{P}$, it has been found to be effective in nutrient delivery to the soil. Cation exchange capacity (CEC) indicates the capacity of a substrate to absorb and exchange soluble cations (Moldes et al., 2007); CEC of wood-based growing medium was higher than that of soil or soil mixed with woodbased growing medium (1:1, w/w); thus, ensuring higher retention of nutrients added.

\subsection{Effect of the different media on plant coverage by $L$. cyrtobotrya}

L. cyrtobotrya was chosen for plant coverage on the slope experimental site. In October, plant coverage for the soil with wood-based growing medium (1:1, w/w) was about 1.2 times greater than that for soil without any addition (Fig. 1). Soil mixed with wood-based growing medium (1:1, w/w) was found to be particularly high in plant coverage of the experimental slope site than the other two media treatments during the entire duration of the experiment. The lower plant coverage in the case of wood-based growing medium by itself could be due to the extremely low $\mathrm{pH}$ and the high EC promoted by it. Garcia et al. (2002) reported that acidic soil conditions can inhibit plant growth, leading to a lower input of plant residues in the soil, which means lower organic $C$ input to the soil and lower soil organic matter content. Low plant coverage when the relative proportion of wood waste was high in the growth medium, resulting in higher EC, was also observed by Sánchez-Monedero et al. (2004) and Bustamante et al. (2008). Our results demonstrate that soil mixed with wood-based growing medium $(1: 1, w / w)$ is suitable for plant coverage on slopes; however, application of wood-based growing medium for restoration of slope vegetation required adjustment of $\mathrm{pH}$ and $\mathrm{EC}$ conditions.

\subsection{Correlation between physicochemical properties of the experimental growth media and plant coverage}

Fig. 2 shows the correlation analysis between plant coverage and soil characteristics affected by woodbased growing medium. The results show that moisture content $(-0.50)$ and CEC (-0.70) had the greatest effect

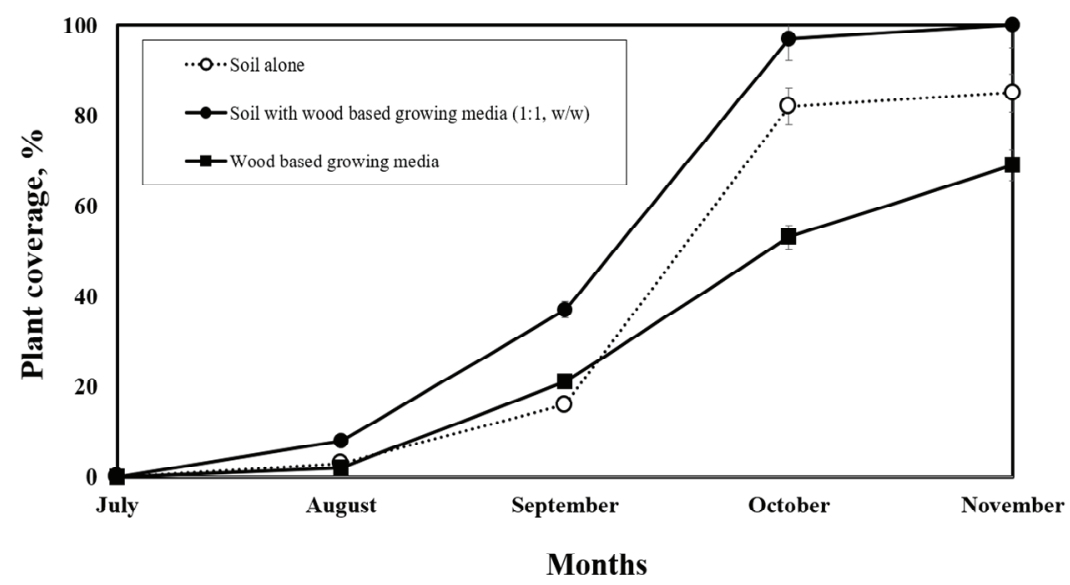

Fig. 1. Effect of different growing media on plant (Lespedeza cyrtobotrya) coverage over the duration of the experimental period. 


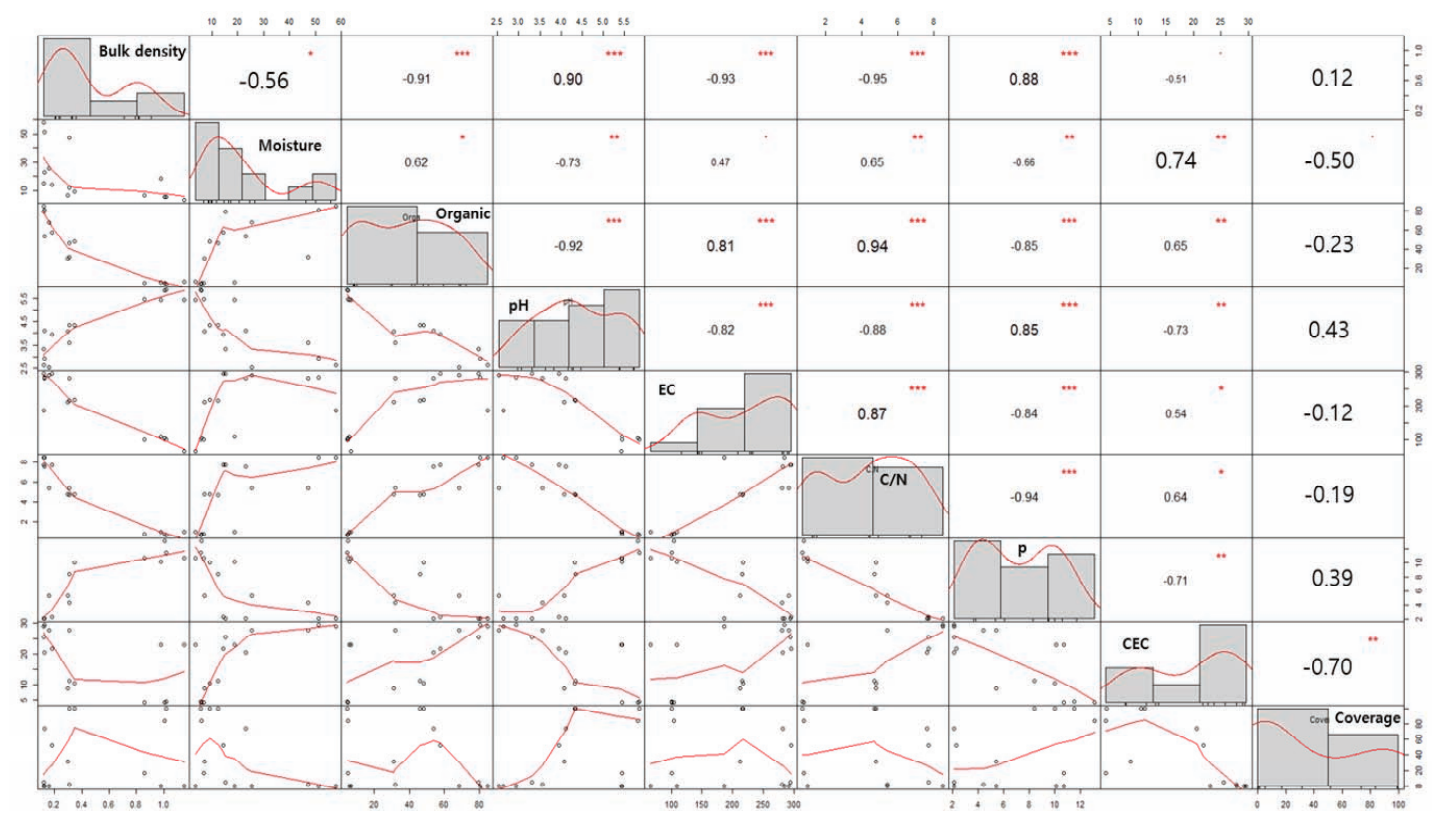

Fig. 2. Correlation between plant coverage and soil characteristics affected by the experimental growing media. *significant at $p \leq 0.05 ;{ }^{* *}$ significant at $p \leq 0.01 ; * * *$ significant at $p \leq 0.001$.

on plant coverage. Haynes and Naidu (1998) also reported effect of moisture content and CEC for plant growth. The direct relationship between plant coverage and soil moisture depletion is consistent with the well-documented bulk density effects on plant coverage and on soil water content (Harper 1977; Jo et al., 2017). The results also confirmed this high correlation (-0.56) between moisture content and bulk density. Zhang and Zhao (2015) reported that water was a very important factor at the initial stages of seedling growth and establishment. Having a relatively high moisture content, natural soil mixed with wood-based growing medium showed faster plant coverage than soil with a lower moisture content (Table 2, Fig. 1). The regression analysis for moisture content and CEC data was calculated using trend line equations in Fig. 3. The relationship between the two variables for soil by itself is described by the following linear equation:

$$
y=0.746 x+5.7127, R^{2}=0.1975
$$

The relationship between the two variables for soil mixed with wood-based growing medium is described by the following linear equation:

$$
y=0.5173 x+6.7509, R^{2}=0.7852
$$

The relationship between the two variables for woodbased growing medium by itself is described by the following linear equation:

$$
y=0.1663 x+19.954, R^{2}=0.6733
$$

Finally, the relationship between the two variables for the pooled data from all media is described by the following linear equation:

$$
\mathrm{y}=0.4033 \mathrm{x}+9.9393, \mathrm{R}^{2}=0.5411
$$

In these three equations, ' $\mathrm{x}$ ' and ' $\mathrm{y}$ ' are the moisture content (\%) and CEC (cmol/kg), respectively, and the 

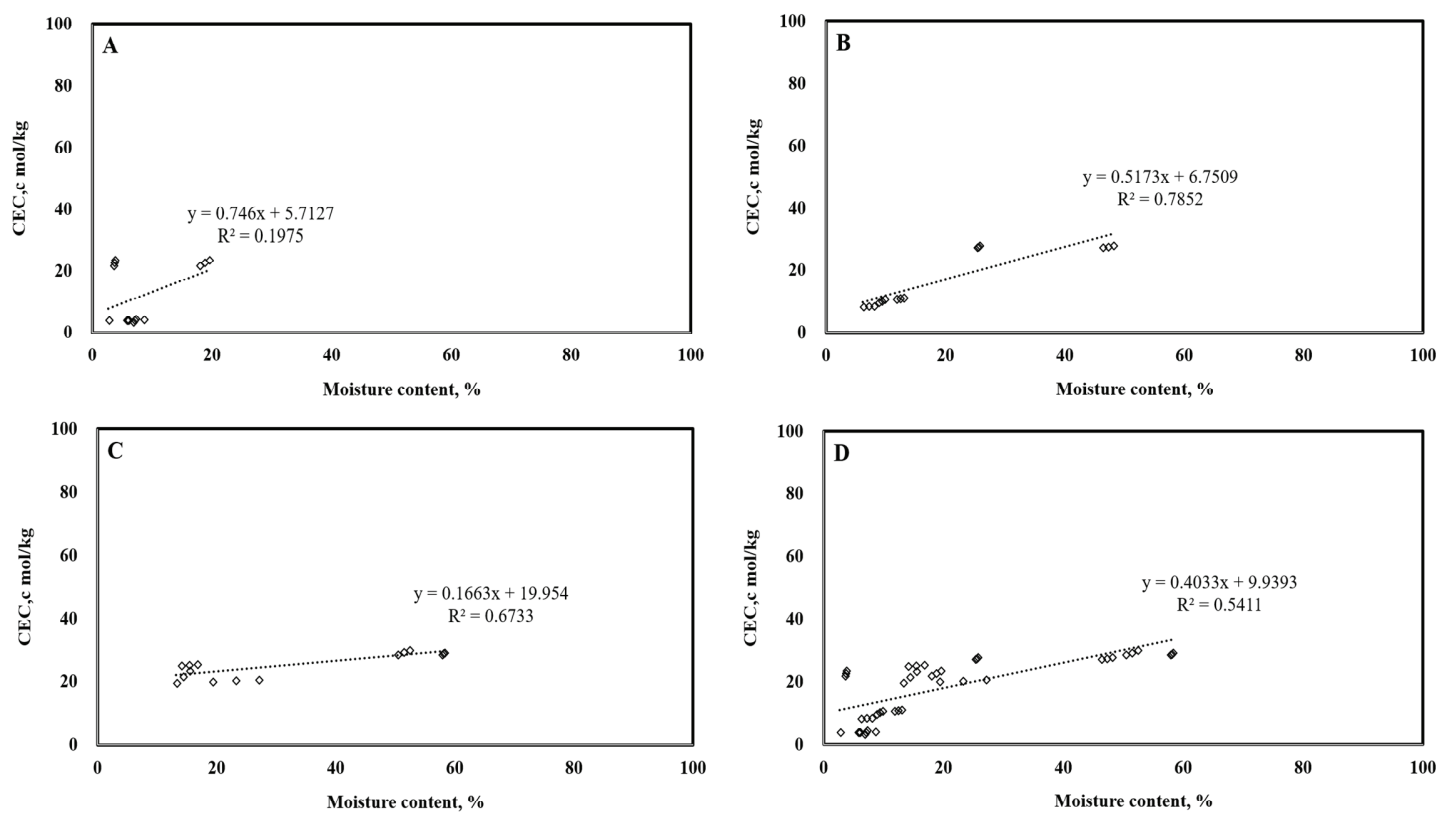

Fig. 3. Regression of CEC on moisture content affected by growing media. A: natural soil; B: soil mixed with wood-based growing medium (1:1, w/w); C: wood-based growing medium; D: pooled data from all growing media tested.

coefficients of determination varied between 0.1975 and 0.7852 .

A scatter diagram of the data from the present study, superimposed with the equations above showed a relatively close fit between the equations and the data from soil mixed with wood-based growing medium $\left(\mathrm{R}^{2}=0.7852\right)$ and wood-based growing medium $\left(\mathrm{R}^{2}=0.6733\right)$. This means that the high moisture content in the two wood-based growing media tested is highly related to CEC. High moisture content of growing media was reported to be related to organic matter and bulk density (Sanchez et al., 1989; Kladivko and Nelson, 1979). Sanchez et al. (1989) reported that as organic matter increased when wood waste was applied to the soil it is not surprising that soil physical properties improve concomitantly. Khaleel et al. (1981) calculated a highly significant linear regression $\left(r^{2}=0.69\right)$ between observed increases in soil organic C. As a result, moisture content is controlled primarily by the number of pores and their pore size distribution and the specific surface area of soils. Because of increased aggregation, total pore space typically increases with addition of organic matter (Kladivko and Nelson, 1979). Furthermore, as bulk density decreases, the relative number of small pores increases (Pagliai et al., 1981), as well as moisture content (Huntington et al., 1989). Our results also indicated a close correlation between organic matter of wood-based growing medium and bulk density. Therefore, wood-based growing medium influenced moisture content and bulk density of the slope soil (Fig. 2). Regression models presented here may be used to estimate with reasonable accuracy CEC from moisture content data; this will prove to be particularly helpful in modeling plant coverage on slopes.

\section{CONCLUSION}

Slopes need to be covered with plants in order to be protected from landslide hazards as well as for landscape conservation. Application of growing media 
is one of the most convenient methods for facilitating plant cover on slopes. In particular, it is necessary to develop growing media based on environmentally friendly materials. Therefore, better management practices in which judicious use of media added with some wood waste are recommended for adoption to enhance plant coverage at a minimum environmental cost.

Here, we studied the individual and integrative effects of wood-based growing media on plant coverage and soil properties. We found that the combined application of wood based growing medium and natural soil improved plant coverage and related attributes of plant growth on the experimental slope. Increased moisture content and CEC due to mixing of soil and wood-based growing medium improved plant coverage and soil characteristics, which in turn promoted plant cover. Therefore, the combined application of wood-based growing medium is considered a good option to enhance plant growth. Additionally, moisture content and CEC were confirmed to be key factors for facilitating plant coverage.

\section{ACKNOWLEDGMENT}

This work was supported by Gyeongnam National University of Science and Technology Grant in 2018 2019.

\section{REFERENCES}

Aggelides, S.M., Londra, P.A. 2000. Effects of compost produced from town wastes and sewage sludge on the physical properties of a loamy and a clay soil. Bioresource Technology 71(3): 253-259.

Bardgett, R.D., Walker, L.R. 2004. Impact of colonizer plant species on the development of decomposer microbial communities following deglaciation. Soil Biology and Biochemistry 36(3): 555-559.

Blake, G.R., Hartge, G.E. 1986. Bulk density. Klute,
A. (Ed.), Methods of Soil Analysis, Part 1. Physical and Mineralogical Methods, Agronomy Monography no. 9, 2nd ed. American Society of Agronomy, Madison, WI, USA, 363-375.

Bremner, J.M., Mulvaney, C.S. 1982. Nitrogen-total. Methods of soil analysis. Part 2. Chemical and microbiological properties American Society of Agronomy, Madison, WI, USA, 595-624.

Bustamante, M.A., Paredes, C., Moral, R., Agulló, E., Pérez-Murcia, M.D., Abad, M. 2008. Composts from distillery wastes as peat substitutes for transplant production. Resources, Conservation and Recycling 52(5): 792-799.

Castleton, H.F., Stovin, V., Beck, S.B.M., Davision, J.B. 2010. Green roofs; building energy savings and the potential for retrofit. Energy and Buildings 42(10): 1582-1591.

Cerdà, A. 1998. Changes in overland flow and infiltration after a rangeland fire in a Mediterranean scrubland. Hydrological Processes 12(7): 1031-1042.

Cho, E., Choi, M., Wagner, W. 2015. An assessment of remotely sensed surface and root zone soil moisture through active and passive sensors in northeast Asia. Remote Sensing of Environment 160: 166-179.

Chong, C., Cline, R.A., Rinker, D.L., 1991. Growth and mineral nutrition status of containerized woody species in media amended with spent mushroom compost. Journal of the American Society for Horticultural Science 116(2): 242-247.

Demeyer, A., Voundi-Nkana, J.C., Verloo, M.G. 2001. Characteristics of wood ash and influence on soil properties and nutrient uptake: an overview. Bioresource Technology 77(3): 287-295.

European Standard 13037. 1999. Determination of pH. Soil improvers and growing media, European committee for standardization, Brussels.

Furley, P.A. 1976. Soil-slope-plant relationships in the northern maya mountains, belize, central America. 
III. Variations in the properties of soil profiles. Journal of Biogeography 3(3): 303-319.

Garcia-Gomez, A., Bernal, M.P., Roig, A. 2002. Growth of ornamental plants in two composts prepared from agroindustrial wastes. Bioresource 83(2): 81-87.

Garcia, C., Hernandez, T., Roldan, A., Martin, A. 2002. Effect of plant cover decline on chemical and microbiological parameters under Mediterranean climate. Soil Biology and Biochemistry 34(5): 635-642.

Gyssels, G., Poesen, J. 2003. The importance of plant root characteristics in controlling concentrated flow erosion rates. Earth Surface Processes and Landforms 28(4): 371-384.

Harper, J.L. 1977. Population Biology of Plants. Academic Press, London. xxii-892.

Haynes, R.J., Naidu, R. 1998. Influence of lime, fertilizer and manure applications on soil organic matter content and soil physical conditions: a review. Nutrient Cycling in Agroecosystems 51(2): 123-137.

Huntington, T.G., Johnson, C.E., Johnson, A.H., Siccama, T.G., Ryan, D.F. 1989. Carbon, organic matter, and bulk density relationships in a forested spodosol. Soil Science 148(5): 380-386.

Jo, J.S., Ha, S.Y., Jung, J.Y., Kim, J.S., Nam, J.B., Yang, J.K. 2017. Effects of lignocellulosic growing media to the prevention of forest soil erosion. Journal of the Korean Wood Science and Technology 45(4): 419-431.

Jung, J.Y., Ha, S.Y., Yang, J.K. 2017. Steam treated sawdust as soilless growing media for germination and growth of horticulture plant. Journal of the Korean Wood Science and Technology 45(6): 857-871

Khaleel, R., Reddy, K.R., Overcash, M.R. 1981. Changes in soil physical properties due to organic waste applications: A review. Journal of Environmental Quality 10(2): 133-141.
Kil, N., Holland, S.M., Stein, T.V., Ko, Y.J. 2012. Place attachment as a mediator of the relationship between nature-based recreation benefits and future visit intentions. Journal of Sustainable Tourism 20(4): 603-626.

Kladivko, E.J., Nelson, D.W. 1979. Changes in soil properties from application of anaerobic sludge. Water Pollution Control Federation 51: 315-332.

Kramer-Paul, J. 1944. Soil moisture in relation to plant growth. Botanical Review. 10(9): 525-559.

Lemaire, F., Dartigues, A., Riviere, L.M., 1985. Properties of substrate made with spent mushroom compost. ActaHort 172(1):13-29.

Marin, J.A. 2004. Biorremediación, mediante técnicas biológicas, de hidrocarburos contenidos en lodos de refineria. Experiencias en Clima Semiárido. $\mathrm{PhD}$ Thesis, Murcia University.

Medina, E., Paredes, C., Pérez-Murcia, M.D., Bustamante, M.A., Moral, R. 2009. Spent mushroom substrates as component of growing media for germination and growth of horticultural plants. Bioresource Technology 100(18): 4227-4232.

Moldes, A., Cendón, Y., Barral, M.T. 2007. Evaluation of municipal solid waste compost as a plant growing media component, by applying mixture design. Bioresource Technology 98(16): 3069-3075.

Nelson, D.W., Sommers, L.E. 1982. Total carbon, organic carbon and organic matter. In: Page, A.L., Miller, R.H., Keeney, D.R. (Eds.), Methods of Soil Analysis, Part 2. Chemical and Microbiological Properties, $2^{\text {nd }}$ edn. (Agronomy series no. 9) ASA, SSSA, Madison, Wis. 539-579.

Ogawa, M., Kuroda, K. 1997. Preparation of inorganicorganic nanocomposites through intercalation of organoammonium ions into layered silicates. Bulletin of the Chemical Society of Japan 70(11): 2593-2618.

Okiror, P., Lejju, J.B., Bahati, J., Rugunda, G.K., Sebuuwufu, C.I., Mulindwa, P., Ocan, J.J. 2017. 
Suitability of Kabanyolo soils for fruit and vegetable production. Scientific Research Publishing. 7(2): 19-33.

Orhan, E., Esitken, A., Ercisli, S., Turan, M., Sahin, F. 2006. Effects of plant growth promoting rhizobacteria (PGPR) on yield, growth and nutrient contents in organically growing raspberry. Scientia Horticulturae 111(1):38-43.

Pagliai, M., Guidi, G., La-Marca, M., Giachetti, M., Lucamante, G. 1981. Effects of sewage sludges and composts on soil porosity and aggregation. Journal of Environmental Quality 10(4): 556-561.

Park, H.D., Wells, G.F., Bae, H., Criddle, C.S., Francis, C.A. 2006. Occurrence of ammonia-oxidizing archaea in wastewater treatment plant bioreactors. Applied and Environmental Microbiology 72(8): 5643-5647.

Park, J.H., Ok, Y.S., Kim, S.H., Cho, J.S., Heo, J.S., Delaune, R.D., Seo, D.C. 2016. Competitive adsorption of heavy metals onto sesame straw biochar in aqueous solutions. Chemosphere 142: 77-83.

Raviv, M., Blom, T.J. 2001. The effect of water availability and quality on photosynthesis and productivity of soilless-grown cut roses. Scientia Horticulturae 88(4): 257-276.

Rosen, C.J., Halbach, T.R., Swanson, B.T. 1993. Horticultural uses of municipal solid waste components. HortTechnology 3(2): 167-173.

Sánchez-Monedero, M.A., Roig, A., Cegarra, J., Bernal, M.P., Noguera, P., Abad, M., Antón, A., 2004. Composts as media constituents for vegetable transplant production. Composts Science \& Utilization 12(2): 161-168.

Sanchez, P.A., Palm, C.A., Szott, L.T., Cuevas, E., Lal, R. 1989. Organic input management in tropical agroecosystems. In: Coleman DC, Oades JM \&
Uehara G (eds) Dynamics of Soil Organic Matter in Tropical Ecosystems, Honolulu, University of Hawaii Press. pp. 125-152.

Senesi, N., Loffredo, E. 1999. The chemistry of soil organic matter. In: Spark, D.L.(Ed). Soil physical chemistry. CRC Press, Boca Raton, FL. pp. 239-370.

Smith, S.R. 1994. Effect of soil pH on availability to crops of metals in sewage sludge-treated soils. I . Nickel, copper and zinc uptake and toxicity to ryegrass. Environmental Pollution 85(3): 321-327.

Soil Conservation Service, USDA. 1972. Soil survey laboratory methods and procedures for collecting soil samples.

Stabnikova, O., Goh, W.K., Ding, H.B., Tay, J.H., Wang, J.Y. 2005. The use of sewage sludge and horticultural waste to develop artificial soil for plant cultivation in Singapore. Bioresource Technology 96(9): 1073-1080.

Walker, L.R., Powell, E.A. 1999. Regeneration of the Mauna Kea silversword Argyroxiphium sandwicense (Asteraceae) in Hawaii. Biological Conservation 89(1): 61-70.

Woo, K.S., Chook, P., Lolin, Y.I., Cheung, A.S.P., Chan, L.T., Sun, Y.Y., Sanderson, J.E., Metreweli, C., Celermajer, D.S. 1997. Hyperhomocyst(e) inemia is a risk factor for arterial endothelial dysfunction in humans. Circulation 96(8): 25422544.

Wright, R.D., Blair-West, J.R., Nelson, J.F. 1986. Effects of ouabain, amiloride, monensin, and other agents on ovine parotid secretion 250(3): F503-F510.

Zhang, Y., Zhao, W. 2015. Vegetation and soil property response of short-time fencing in temperate desert of the Hexi Corridor, northwestern China. CATENA 133: 43-51. 